\title{
GERADORES DE SISTEMAS DE APOIO À DECISÃO E SEU USO NUM PROCESSO DE GESTÃO ORÇAMENTÁRIA
}

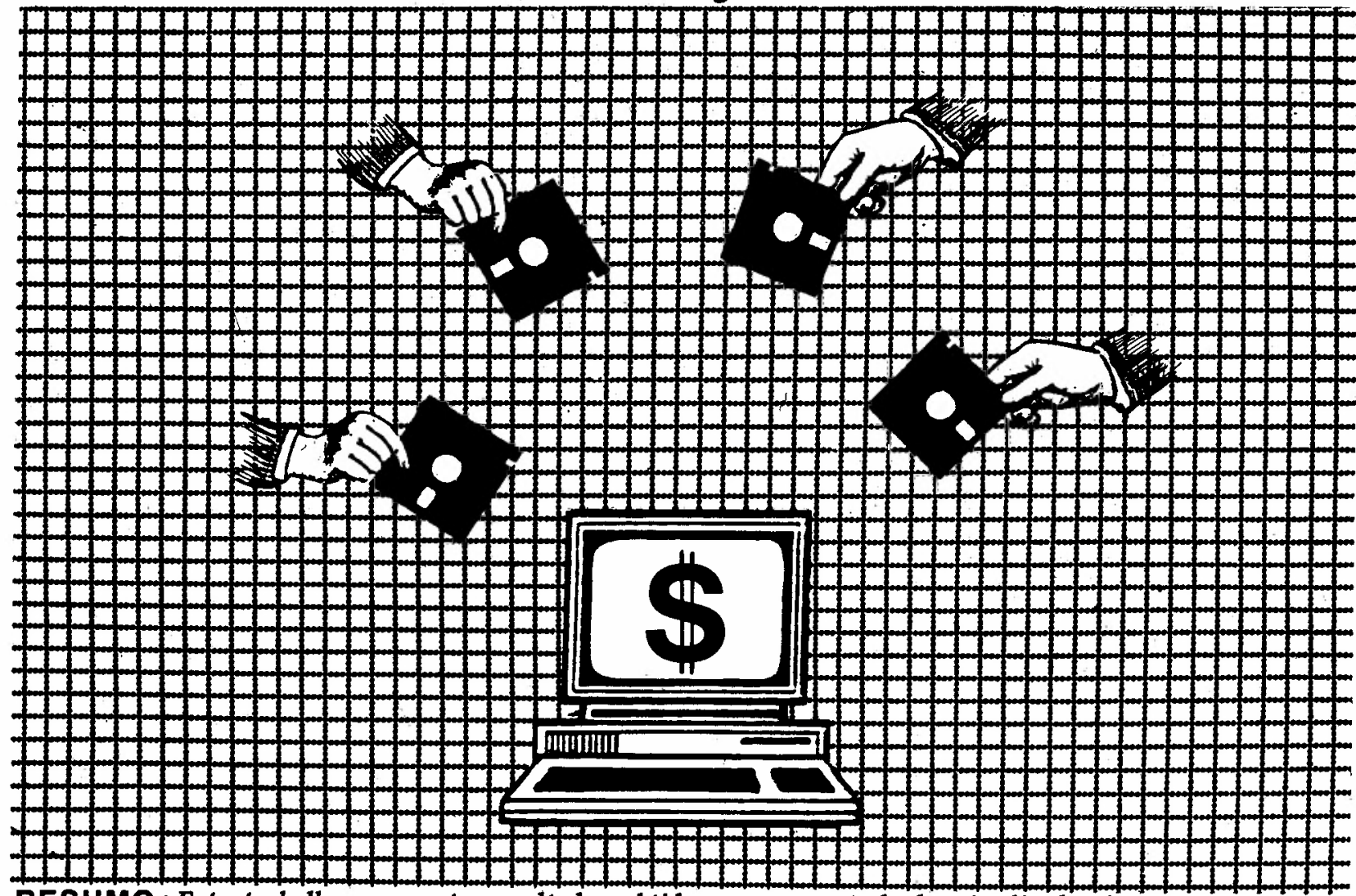

RESUMO: Este trabalho apresenta resultados obtidos em um estudo longitudinal sobre o uso de Geradores de Sistemas de Apoio a Decisðo-GSAD num processo de gestão orçamentária. Säo apresentadas características de acessibilidade dos geradores, do processo de desenvolvimento, a partir dos geradores, de Sistemas de Apoio à Decisao-SAD específicos, e do apoio à decisão fornecido. A partir destes resultados, são indicadas vias para o desenvolvimento $e$ aperfeiçoamento dos GSAD para gestão orçamentária.

PALAVRAS-ChaVe: Apoio d̀ Decisdo, Sistemas de Apoio d̀ Decisăo, Geradores de Sistemas de Apoio d Decisão, Gestão Orçamentária.

\section{Norberto Hoppen}

Professor no Departamento de Ciéncias Administrativas e do Programa de Pós-Graduação em Administração da Universidade Federal do Rio Grande do Sul.

\section{- Lúcla G. Esperança}

Aluna do Curso de Ciência da Computação da Universidade Federal do Rio Grande do Sul.

Esta pesquisa conta com o apolo da CAPES e do CNPq.
Embora diversos estudos já tenham sido realizados sobre o impacto dos Sistemas de Apoio a Decisão - SAD - num processo decisório individual ${ }^{1}$, poucos abordaram o processo de desen-

1. VER: AJENSTAT, Jacques. "Fondements théoriques et étude d'impacte d'un Système Interactif d'Aide à la Decision". Th'se de Doctorat de 3ème Cycle. França, IAE d'Aix en Provence, defendida em 23 de novembro de 1983, 555 páginas; e BAILE, Serge. "Une révue des modèles de gécision stratégique: apport conceptuel pour l'étude empirique de la performance des SSD en gestion". In: Papier de recherche n. 6/85. França, CESSIAG, Groupe ESC Toulouse, décembre, 1985. 
volvimento e de utilização desses sistemas. Com o objetivo de estudar o uso de Geradores de Sistemas de Apoio à Decisão - GSAD num processo de gestão orçamentária, realizouse um estudo longitudinal, que utilizou a análise de protocolo como método. Neste trabalho, apresentam-se alguns dos resultados obtidos.

GSAD são pacotes de software que permitem a realização de Sistemas de Apoio à Decisão SAD - específicos, sendo constituídos de ferramentas de modelagem, gestão de dados, processamento de textos e de gráficos, comunicação e outros. No estudo realizado foram empregados dois tipos de geradores: um, com um grande número de ferramentas, denominado gerador integrado, e um segundo, composto essencialmente de uma planilha eletrônica. $O$ uso destes dois tipos de geradores objetivou a análise das diferenças de realização e utilização de SAD e do apoio à decisão prestado ao processo de gestão orçamentária.

Este texto apresenta, inicialmente, as definições de GSAD, SAD e apoio à decisão. A seguir, é descrito o planejamento do experimento, realizado em laboratório, que permitiu o estudo longitudinal do processo de gestão orçamentária. A análise dos dados obtidos é apresentada em seguida e, a partir destes resultados, são indicadas vias para o desenvolvimento e aperfeiçoamento dos GSAD para gestão orçamentária.

\section{SAD, GSAD E APOIO À DECISÃO}

Nesta seção, são apresentadas as definições de SAD e GSAD, algumas características essenciais dos GSAD, e o modelo decisório adotado para o estudo do apoio à decisão.

\section{SAD e GSAD: Definlçбes}

Um SAD é, segundo Courbon ${ }^{2}$, um sistema homem-máquina que, através do diálogo, permite a um tomador de decisão ampliar o seu raciocínio quando da identificação e resolução de problemas pouco estruturados. Um SAD pode ser desenvolvido a partir de linguagens de programação tradicionais, tais como Pascal e Basic, a partir de geradores como Framework, FCS e IFPS, e a partir de ferramentas específicas ${ }^{3}$. O presente trabalho limita-se ao estudo do desenvolvimento de SAD a partir de geradores implantados em microcomputadores.

Um GSAD é um conjunto de programas (softwares), agrupados em módulos, e de hardware. Ele deve ter a capacidade de fornecer ferramentas especializadas de modelagem, gestão de dados, processamento de textos e gráficos e comunicação para a realização de $\mathrm{SAD}$ es- pecíficos ${ }^{4}$. Um GSAD é, pois, ao mesmo tempo, uma ferramenta de desenvolvimento - o gerador - e uma ferramenta de apoio à decisão para um ou mais problemas específicos - $O$ (s) SAD gerado(s). Dentre as diferentes características dos GSAD, neste texto são estudados a acessibilidade e a necessidade de integração das ferramentas, os recursos de modelagem empregados para a realização de SAD e o apoio à decisão obtido com os SAD específicos durante o desenrolar do processo de gestão orçamentária.

\section{Acessibillidade e Integraçáo}

$A$ acessibilidade de um GSAD está relacionada com as suas características "amigável", "fácil de usar" e "orientado para o usuário"s. Estas características só podem ser operacionalizadas quando se define o usuário do sistema, por exemplo "fácil de usar por quem e a que momento"?. Neste estudo, as características associadas à acessibilidade do GSAD foram analisadas no momento do aprendizado e quando do seu uso pelos tomadores de decisão observados.

Segundo Methlie ${ }^{6}$, um SAD específico tem uma vida relativamente curta, pois evolui constantemente. Em função disso, deve ser criada uma infra-estrutura para o sistema, da qual fazem parte a assistência técnica, banco de dados e comunicação. Esta infra-estrutura torna o processo de concepção e uso do SAD mais fácil. Neste estudo, em razão das restrições de nível tecnológico do laboratório, em termos de comunicação e interligação com banco de dados, a análise da infra-estrutura restringiu-se à dispo-

2. COURBON, Jean Claude. "Les SIAD: outil, concepts et mode d'action". In: AFCET-Interfaces, $\mathrm{n}^{2} 9$, juillet, 1983, pp. 30-36.

3. HOPPEN, Norberto e TRAHAND, Jacques. "Os Geradores de Sistemas de A poio à Decisão para o planejamento orçamentário e financeiro". In: Revista de Administração, vol. 20, n 4, outubro-dezembro, 1985 , pp. 51-62.

4. SPRAGUE, Ralph H. e CARLSON, Eric D. Building Effective Decision Support Systems. Englewood Cliffs, Prentice-Hall, 1982.

5. SILVEIRA, Sandra R. B. da e COLANGELO FILHO, Lúcio. "Á plicaçôes atrativas: receitas comentadas". In: Anais do XX Congresso Nacional de Informática. São Paulo, SUCESU, setembro, 1987, pp. 137-141; e ZWICKER, Ronaldo e REINHÁRD, Nicolau. "Interfaces de Sistemas: a importancia dos fatores humanos". In: Anais do XX Congresso Nacional de Informática. São Paulo, SUCESU, setembro, 1987, pp. 1078-1084.

6. METHLIE, Leif B. "Organizational Variables Influencing DSS-Implementation". In: SOL, H. G. (org.) Processes and Tools for Decision Support. North Holland Publishing Co., 1983, pp. 93-104. 


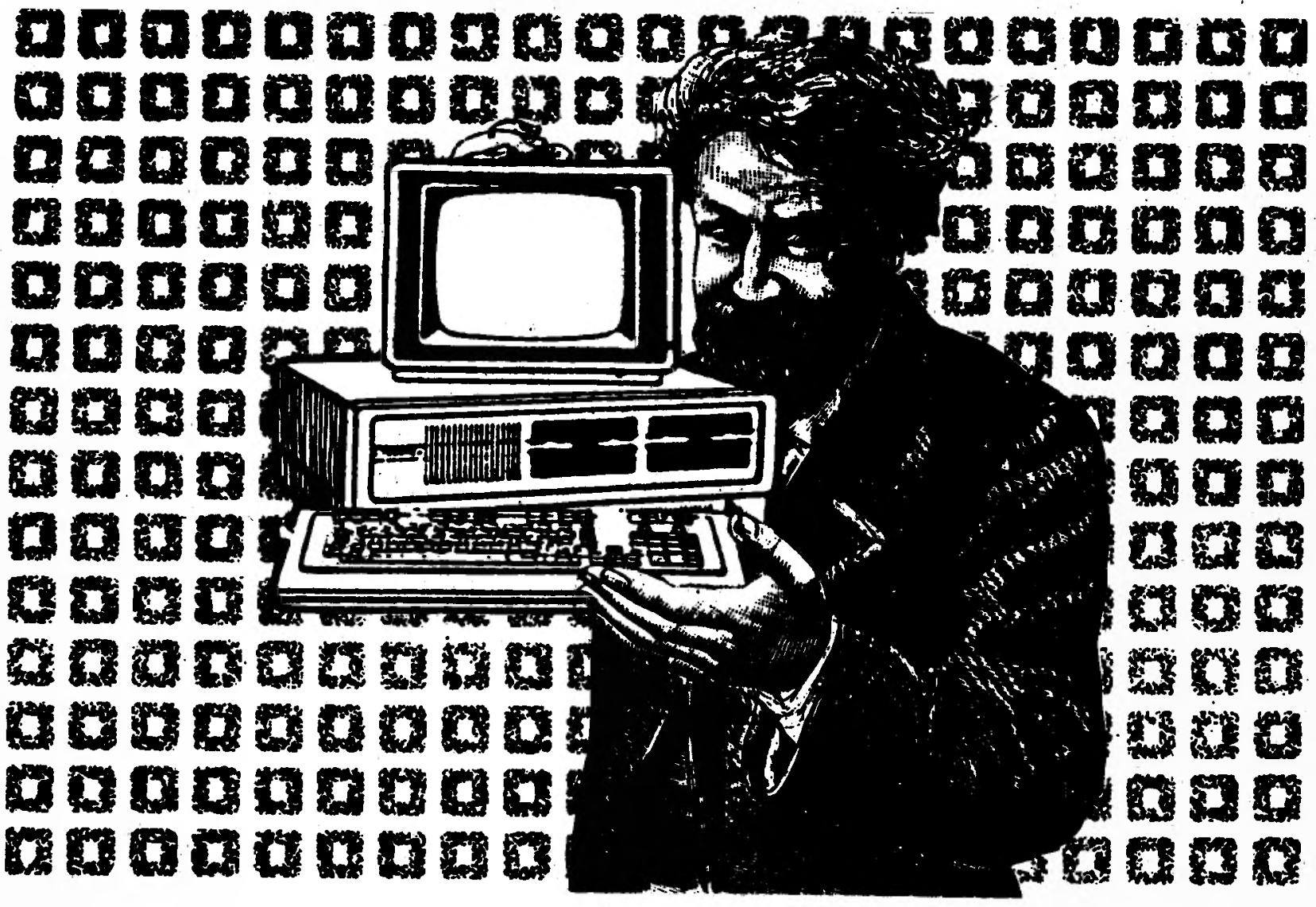

nibilidade do sistema e da assistência técnica.

Os GSAD são estruturados a partir de ferramentas para a realização de SAD. Conseqüentemente, os geradores devem oferecer os recursos de que o usuário necessita para o desenvolvimento de seu(s) SAD. A maior ou menor abrangência destes recursos é aqui caracterizada como integração. A operacionalizaçăo do conceito, "recursos necessários para quem e a que momento?", é difícil. Como integração foram pois analisados as funcionalidades oferecidas pelo gerador e os recursos efetivamente utilizados pelo usuário, quando da concepção dos SAD.

\section{Apolo à Declsăo e Gestáo Orçamentárla}

A gestão orçamentária pode ser resumida pelos seguintes procedimentos:

\section{1. fixação dos objetivos;}

2. estabelecimento de um programa de ação, composto de previsão de vendas, da definição dos níveis de atividade e dos custos, e traduzido monetariamente no orçamento; $e$

3. acompanhamento da execução, através da análise dos desvios e da tomada de decisões corretivas.
Estes procedimentos estăo resumidos na figura 1. A gestão orçamentária é uma atividade pouco estruturada. Pode-se constatar a presença de objetivos múltiplos e por vezes conflitantes nesta seqüência, e o tipo de processamento realizado com os dados năo é automatizável na sua

\section{FIG. 1: O Processo de Gestăo Orçamentárla}




FIG. 2: Processo Declsórlo e Atos Reallzeivels com um GSAD ou SAD

\begin{tabular}{|c|c|c|c|c|}
\hline \multicolumn{2}{|c|}{ Proceseo Deckbrio } & \multicolumn{3}{|c|}{ Agoes Realtzadas com o auxflio de um GSAD ou SAD } \\
\hline Fases & $\begin{array}{c}\text { Atividades de Tomada } \\
\text { de Decisazo }\end{array}$ & $\begin{array}{l}\text { Sobre os dados, } \\
\text { modelos } \theta \\
\text { gráficos }\end{array}$ & $\begin{array}{l}\text { Para a apresentaçăo } \\
\text { dos resultados: } \\
\text { tabelas, gráficos } \\
\text { e relatórios }\end{array}$ & $\begin{array}{l}\text { Operaçóes indepen- } \\
\text { dentes do processo } \\
\text { decisório (manipula- } \\
\text { ça do sistema) }\end{array}$ \\
\hline $\begin{array}{l}\text { Modelagem } \\
\text { Escolha }\end{array}$ & 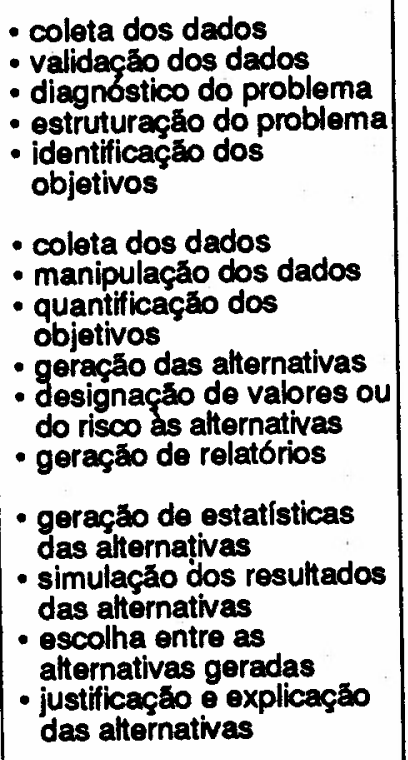 & $\begin{array}{l}\text { Construir SAD } \\
\text { Modificar } \\
\text {-dados } \\
\text { - modelos } \theta \\
\text { dados } \\
\text { - por recálculo } \\
\text { somente } \\
\text { Consultar SAD } \\
\\
\text { Interrupçáo } \\
\text { do trabalho } \\
\text { Usar outros } \\
\text { softwares }\end{array}$ & $\begin{array}{l}\text { Consultar SAD } \\
\text { Imprimir } \\
\text { Apresentar na } \\
\text { tela } \\
\text { Interrupçăo } \\
\text { do trabalho } \\
\text { Usar outros } \\
\text { softwares }\end{array}$ & $\begin{array}{l}\text { Manipular na RAM } \\
\text { do microcomputa- } \\
\text { dor: } \\
\text { - destruir arquivo } \\
\text { - abrirfiechar } \\
\text { arquivos } \\
\text { Carregar DOS } \\
\text { Carregar GSAD } \\
\text { Sair do GSAD } \\
\text { Formatar } \\
\text { disquete } \\
\text { Configurar } \\
\text { Impressoral } \\
\text { micro } \\
\text { Copiar/destruir } \\
\text { arquivos no } \\
\text { disquete } \\
\text { Carregar } \\
\text { arquivos } \\
\text { Consultar conteúdo } \\
\text { disquete } \\
\text { Escolher unidade } \\
\text { de disco default }\end{array}$ \\
\hline
\end{tabular}

integralidade, pois não existem modos de raciocínio ou decisőes-padrão ${ }^{7}$.

Neste estudo, observou-se o uso de GSAD e de SAD específicos no processo de orçamentação, através da análise das açōes realizadas pelos usuários-tomadores de decisão com os geradores, quando da concepçăo dos SAD, e com os SAD específicos, quando procuraram obter apoio à decisão. A análise fundamentou-se no modelo de decisão de Simon $^{8}$ e na abordagem ROMC ${ }^{\circ}$. O primeiro modelo considera o processo decisório individual como uma seqüência de três fases: inteligência, modelagem e escolha. Elas consistem respectivamente na identificação do problema, na modelagem das soluçőes possíveis e na seleção da solução satisfatória, podendo-se acrescentar a fase de implementação ao modelo original. Com base nesse modelo de decisão, Sprague e Carlson explicitaram as principais atividades de tomada de decisão que compõem cada uma das fases. A partir destas atividades, foram definidas ações que são realizadas com um GSAD quando do desenvolvimento e da utilização de SAD específicos - ver figura 2.

Estas ações podem ser agrupadas em ações re- lacionadas diretamente com o processo decisório - construir, modificar, consultar e imprimir a tabela, o gráfico, o relatório - e em ações independentes do processo decisório, mais diretamente relacionada com o uso de hardware e software no GSAD. As açōes, por sua vez, são compostas de códigos de ação, elaborados a partir dos menus e submenus, das teclas de função e outros comandos especiais do teclado, assim como das funções de programação existentes no GSAD. A observação detalhada das ações e dos seus respectivos códigos de ação, durante o processo de gestão orçamentária tornou possível a análise das diferenças de uso dos dois tipos de GSAD adotados, o estudo da efetiva utilização dos recursos existentes nos geradores e a análise do apoio à decisão oferecido pelos SAD específicos nas três fases do processo decisório.

7. TOLOVI JR., José e GRAJEW, Jakow. "A informática e a tomada de decisóes na empresa: perspectivas para os anos 80." In: Revista de Administração de Empresas, vol. 20, $n^{\circ} 4$, out-dez., 1980, pp. 45-50.

8. SIMON, Herbert A. The new science of management decisions. New York, Harper \& Row, 1960.

9. SPRAGUE, Ralph H. e CARLSON, Eric D. Op. cit. 


\section{PLANEJAMENTO DO EXPERIMENTO}

Nesta seção, estão descritos o processo de gestão orçamentária observado, os usuários que dele participaram e os GSAD utilizados.

\section{O Processo de Gestáo Orçamentária Observado}

O processo de gestão orçamentária foi observado num laboratório experimental, no qual foram criadas, artificialmente, as condições de funcionamento de uma empresa. O laboratório foi organizado na École Supérieure des Affaires de Grenoble, França. Os seguintes elementos fizeram parte do laboratório:

um simulador de gestão, IMAGE I ${ }^{10}$, que simula o funcionamento de uma empresa do setor de componentes elétricos; o modelo é global e sem concorrência, as funções clássicas de uma empresa estão representadas - pessoal, suprimento, produção etc. - e uma característica importante de qualquer processo de gestão, $a$ incerteza, está presente;

- um processo de gestão orçamentária que permite administrar a empresa durante um ano;

um comitê de direção, composto pelos cinco ou seis usuários pontenciais do GSAD e dos SAD;

- animadores do processo de gestão orçamentária com IMAGE I, que dirigem a simulação;

conselheiros que prestam assistência técnica para o uso do GSAD;

um GSAD e um microcomputador equipado com impressora, ferramentas computacionais para previsão e programação da produção, $\mathrm{e}$ dados sobre os 24 últimos meses de atividade da empresa gravados em disquete;

um equipamento para a gravação, em vídeo, dos dados referentes à interação usuárioGSAD-microcomputador.

O processo orçamentário propriamente dito é composto de duas grandes etapas: a análise do passado e a gestão previsional. A etapa de análise do passado (24 meses) da empresa gerida resulta na fixação dos objetivos para a administração da empresa para os próximos 12 meses. Nesta etapa, são realizadas essencialmente atividades correspondentes às fases inteligência e modelagem do modelo decisório de Simon ${ }^{11}$. $\mathrm{Na}$ etapa de gestão previsional e real da empresa por um período de 12 meses, as principais atividades são a análise do mercado e as previsões de vendas, a administração de pessoal, a programação da produção e do suprimento, a previsão do fluxo de caixa, a aplicação das escolhas feitas e $\mathrm{a}$ análise de suas conseqüểncias. Essas atividades correspondem às fases modelagem e escolha do modelo do processo decisório de Simon, e também à implementação das decisões escolhidas. As atividades da gestão previsional são interdependentes e compõem-se de 23 decisões elementares, tais como niveis de produção e suprimento. Essas decisões devem ser tomadas para o bom andamento da administração da empresa simulada. As 23 decisões encontram-se em diferentes modelos - os SAD específicos - desenvolvidos pelos usuários.

\section{Os Grupos de Usuários}

Dois comitês diretores - grupos A e B foram escolhidos para o experimento, dentre os participantes da simulação com IMAGE I. Cada um dos grupos empregou um GSAD diferente em termos de integração de ferramentas ou módulos especializados. Os membros do grupo são executivos de empresas da região de Grenoble, França. Eles encontravam-se na fase de conclusão de um programa de especialização de administração de empresas, a nível de pós-graduação, com duração de dois anos.

As características dos integrantes dos dois grupos, dos quais nenhum tinha experiência com simuladores de gestão, estão apresentadas no quadro 1.

As características acima indicam que os usuários que participaram do experimento poderiam constituir um grupo semelhante aos gerentes-tomadores de decisão encontrados nas empresas, em termos de estudos, experiência profissional e experiência com informática. Essas características também mostram que o grupo $B$ tinha uma maior experiência no uso de ferramentas computacionais.

Dos cinco componentes do grupo A, quatro tornaram-se usuários de $\mathrm{SAD}$, ao passo que no grupo $B$, todos os seis integrantes utilizaram SAD.

\section{Os GSAD Utilizados}

Como GSAD não integrado adotou-se a planilha Multiplan, em sua versão 1 , e como GSAD integrado Framework, também em sua versão 1 . As características destes dois geradores estão apresentadas no quadro 2 .

Em razão do grande número de módulos e do maior número de códigos de ação e funções de programação, Framework foi considerado

10. IMAGE: modelo de simulacão de administração industrial. Documento do IAE de Grenoble (inédito), 1985, 45 páginas.

11. SIMON, Herbert A. Op. cit. 
QUADRO 1: Caracteristicas dos Grupos de Usuários dos GSAD

\begin{tabular}{|c|c|c|}
\hline $\begin{array}{l}\text { Caracteristicas } \\
\text { Pessoais }\end{array}$ & Grupo A & Grupo B \\
\hline - Número de pessoas & 5 & 6 \\
\hline $\begin{array}{l}\text { Idade: faixa dos } 25-34 \text { anos } \\
\text { faixa dos 35-44 anos }\end{array}$ & $\begin{array}{l}1 \\
4\end{array}$ & $\begin{array}{l}2 \\
4\end{array}$ \\
\hline $\begin{array}{l}\text { Estudos } \\
\text { - técnico-científicos } \\
\text { - contábeis-administrativos } \\
\text { - ciências humanas }\end{array}$ & $\begin{array}{l}3 \\
1 \\
1 \\
\end{array}$ & $\begin{array}{r}3 \\
2 \\
1 \\
\end{array}$ \\
\hline $\begin{array}{c}\text { - Formação Multiplan (duração) } \\
\text { Framework }\end{array}$ & $\begin{array}{l}2,5 \text { dias } \\
-\end{array}$ & $\begin{array}{l}1 \text { dia } \\
3 \text { dias } \\
\end{array}$ \\
\hline $\begin{array}{cc}\text { Experiência anterior com } \\
\text { informática: } \\
\begin{array}{l}\text { Multiplan } \\
\text { Grandes sistemas }\end{array}\end{array}$ & $\begin{array}{l}1 \\
- \\
\end{array}$ & $\begin{array}{l}1 \\
2 \\
\end{array}$ \\
\hline $\begin{array}{l}\text { Empresas de origem } \\
\text { - serviços } \\
\text { - indústria } \\
\text { - comércio }\end{array}$ & $\begin{array}{l}2 \\
2 \\
1\end{array}$ & $\begin{array}{l}2 \\
2 \\
2 \\
\end{array}$ \\
\hline Experiência profissional & $>4$ anos & $>4$ anos \\
\hline
\end{tabular}

um GSAD que possui um nível elevado de integração e Multiplan, um nível baixo ${ }^{12}$.

\section{ANÁLISE DO USO DOS GSAD NO PROCESSO DE GESTÃOO ORÇAMENTÁRIA}

O uso dos GSAD no processo de gestão orçamentária foi analisado em termos de acessibilidade dos pacotes de software para os usuários-tomadores de decisão, em termos das características do desenvolvimento e uso dos SAD específicos e em termos do apoio à decisão fornecido.

\section{Uso dos GSAD e Acessibilidade}

$A$ acessibilidade dos GSAD não integrados e integrados, para os usuários dos Grupos A e B, respectivamente, foi estudada no momento do aprendizado inicial dos geradores e durante $o$ seu uso. $O$ aprendizado inicial foi avaliado quando da conclusão dos programas de treinamento aos pacotes de software. $\mathrm{O}$ conteúdo dos dois programas, na medida do possível, foi semelhante e seguiu os mesmos princípios de aumento gradual da complexidade. Os instrutores também foram os mesmos. As características mensuradas após o treinamento inicial estão apresentadas no quadro 3.
A avaliação do aprendizado do gerador não integrado apresenta escores médios superiores aos do integrado, com $91 \%$ dos escores individuais dos usuários do gerador não integrado $\geq 5$ (sobre 6) , contra somente $75 \%$ dos usuários do integrado. Considerando que os usuários do GSAD integrado tinham o mesmo nível de expectativa antes do início do programa de treinamento que os do não integrado - escore médio 5 (sobre 6) -, que os primeiros tinham uma experiência maior com ferramentas computadorizadas, que a duração do seu programa de treinamento foi superior, e que a sua complexidade é menor - em razão do número mais reduzido de módulos, códigos de ação e funções -, pode-se inferir que o aprendizado inicial do gerador não integrado foi mais fácil. Esta constatação é corroborada pelos escores médios sensivelmente mais baixos dados pelos usuários do GSAD integrado à quantidade de trabalho e ao ritmo do programa de treinamento - 4,5 e 4,8 (sobre 6) -,

12. HOPPEN, Norberto. "L'utilisation de Générateurs de Systèmes Interactifs d'Aide à la Décision dans un processus de gestion budgétaire". In: Actes $d u$ Colloque sur le Développement des Sciences et Pratiques de l'Organisation. Paris, AFCET, 10-12 março, 1987, pp. 157-163. 
QUADRO 2: Os GSAD Utilizados

\begin{tabular}{|c|c|c|}
\hline Gerador $\rightarrow$ & $\begin{array}{c}\text { Multiplan } \\
\text { NÃO INTEGRADO }\end{array}$ & $\begin{array}{l}\text { Framework } \\
\text { INTEGRADO }\end{array}$ \\
\hline \multicolumn{3}{|l|}{ soft ware } \\
\hline $\begin{aligned} \square & \text { Módulos } \\
& \text { - número } \\
& \text { descrição }\end{aligned}$ & $\begin{array}{c}1 \\
\text { planilha }\end{array}$ & $\begin{array}{l}6 \\
\text { planilha, banco de dados, } \\
\text { processador de textos e gráticos, } \\
\text { organizador de idéias e comunicação }\end{array}$ \\
\hline $\begin{array}{l}\text { Códigos de Ação (total) } \\
\text { - menu/sub-menu } \\
\text { - teclas de função } \\
\text { - comandos especiais } \\
\text { de teclado }\end{array}$ & $\begin{array}{r}107 \\
94 \\
1 \\
12\end{array}$ & $\begin{array}{r}131 \\
102 \\
10 \\
19\end{array}$ \\
\hline $\begin{array}{l}\text { Funções (total) } \\
\text { - matemáticas } \\
\text { - lógicas } \\
\text { - financeiras } \\
\text { - de impressão } \\
\text { - de automação (macros) } \\
\text { - outras }\end{array}$ & $\begin{array}{r}40 \\
17 \\
10 \\
1 \\
- \\
- \\
12\end{array}$ & $\begin{array}{r}145 \\
20 \\
9 \\
6 \\
22 \\
16 \\
72\end{array}$ \\
\hline \multicolumn{3}{|l|}{ Hardware } \\
\hline Micros & $\begin{array}{l}\text { Hewlett-Packard } 150 \\
256 \mathrm{~K}, 2 \text { disquetes }\end{array}$ & $\begin{array}{l}\text { Olivetti M24 } 512 \mathrm{~K} \text {, } \\
1 \text { disquete + disco rígido } \\
\text { e Bull Micral } 30,640 \mathrm{~K} \text {, } \\
2 \text { disquestes }\end{array}$ \\
\hline - Impressoras & HP e OKI & NEC \\
\hline
\end{tabular}

QUADRO 3: Acessibilidade: Avaliaçáo do Programa de Treinamento Inicial

\begin{tabular}{|ccc|}
\hline Gerador $\rightarrow$ & Não Integrado & Integrado \\
\hline Duração do Programa & $1+1,5$ dias & 3 dias \\
\hline Avaliação do Programa (escore médio sobre 6) & & \\
\hline - Conteúdo & 5,4 & 4,9 \\
- Organização & 5,6 & 5,2 \\
- Instrutores & 5,3 & 5,0 \\
\hline
\end{tabular}

contra os escores 5,4 dados pelos usuários do GSAD não integrado.

A análise das facilidades e/ou dificuldades encontradas quando do uso dos geradores foi realizada a partir:

da mensuração da assistência técnica solicitada pelos usuários;

- da avaliação, pelos usuários, da infraestrutura criada para o uso dos geradores du- rante a simulação ;

da mensuração dos erros efetuados pelos usuários - incorreções relativas aos códigos de ação - quando do uso dos geradores e dos SAD específicos;

da computação, nos menus dos geradores, dos niveis dos códigos de ação utilizados níveis 1, 2 e 3-, tendo em vista que ao nivel 1 corresponde uma única operação por parte do usuário e ao nivel 3 correspondem três operações. 
A observação da assistência técnica solicitada pelos usuários - ver quadro 4 apresentado a seguir - revelou que:

não foram constatadas diferenças sensíveis quanto ao número de intervenções solicitadas;

o GSAD não integrado apresentou um problema específico com a troca freqüente de impressoras, obrigando os usuários a parametrizá-las através da digitação de um código hexadecimal;

- o "consumo" excessivo de memória do GSAD integrado causou problemas para o seu uso, em virtude da limitação do sistema operacional DOS em gerir somente $640 \mathrm{~K}$ de memória central, exigindo assim muitos artifícios de manipulação de arquivos por parte dos usuários;

- a disponibilidade e o uso de um maior número de módulos do GSAD integrado exigiu mais assistência técnica.

Vejam-se, por exemplo, as perguntas relativas ao editor de gráficos.

Outros problemas observados durante o uso do gerador integrado foram os tempos de impressão de tabelas e gráficos, considerados longos pelos usuários (entre 2 e 4 minutos), principalmente quando ocasionaram interrupção no processo decisório coletivo. Por sua vez, a possibilidade de trabalhar com vários frames ou modelos simultaneamente na memória central dificultou o trabalho dos usuários menos experientes.
A infra-estrutura disponível para o uso dos geradores não integrado e integrado pode ser considerada satisfatória em função dos escores obtidos - ver quadro 4 -, mas não foi percebida da mesma maneira pelos usuários. Houve uma maior necessidade de assistência técnica durante as sessões de trabalho livre por parte dos usuários do gerador integrado, quando ocorreram problemas de recuperação de arquivos, de escala nos gráficos e de impressão dos gráficos. Estes não foram resolvidos imediatamente em razão da indisponibilidade momentânea da assistência técnica. O escore de 4,6 (sobre 6) provavelmente é reflexo destes fatos. Também houve pressões para uma maior disponibilidade de hardware e de software durante a simulação escore 4,5-, resultante, ao menos em parte, da limitação de memória útil disponível para o GSAD integrado. Esta demanda resultou no fornecimento de um segundo microcomputador e de um segundo exemplar do software a os usuários do gerador integrado. O escore de 4,8 dado à disponibilidade de hardware e software pelos usuários do GSAD não integrado reflete a necessidade de uma maior disponibilidade de impressora, considerada insuficiente durante a simulação.

A observação dos erros cometidos pelos usuários nos diferentes códigos de ações - ver quadro 5 - permite os seguintes comentários:

- O uso mais regular do gerador não integra-

QUADRO 4:

Acessibilidade: Natureza da Assistêncla Técnica e Infraestrutura Disponível

\begin{tabular}{|c|c|c|c|}
\hline Gerador -> & Não Integrado & \multicolumn{2}{|c|}{ Integrado } \\
\hline \multicolumn{4}{|l|}{ Assistêncla Técnlca } \\
\hline $\begin{array}{l}\text { Total de solicitaçōes } \\
\text { - planilha } \\
\text { - impressão } \\
\text { - sistema operacional e } \\
\text { manipulação de arquivos } \\
\text { - gráficos } \\
\text { - outros }\end{array}$ & $\begin{array}{r}100 \% \\
37 \% \\
25 \% \\
38 \% \\
- \\
-\end{array}$ & 28 & $\begin{array}{c}100 \% \\
40 \% \\
- \\
30 \% \\
15 \% \\
15 \%\end{array}$ \\
\hline \multicolumn{4}{|c|}{ Infraestrutura Disponivel para o Uso dos GSAD (escore médio sobre 6) } \\
\hline $\begin{array}{l}\text { - avaliação da assistência } \\
\text { técnica durante a simulação } \\
\text { - avaliaçăo da assistência } \\
\text { técnica durante o trabalho livre } \\
\text { - disponibilidade de hardware } \\
\text { e de software }\end{array}$ & $\begin{array}{l}5 \\
5,2 \\
4,8\end{array}$ & & $\begin{array}{r}5,4 \\
4,6 \\
4,5\end{array}$ \\
\hline
\end{tabular}


do pelos quatro usuários do grupo acabou gerando um nível médio de erros maior - $8,7 \%$ contra 6,3\% dos usuários do GSAD integrado -, o que pode ser explicado por um uso individual menos intensivo e um aprendizado menor. Dentre os usuários do GSAD não integrado, o mais ativo empregou $40 \%$ do total de códigos de ação observados (3404) e cometeu, em média,
$7,7 \%$ de erros. O usuário menos ativo, por sua vez, utilizou o gerador em $10 \%$ do total e cometeu em média $5,4 \%$ de erros. Entre os usuários do gerador integrado ocorreu uma maior concentração e especialização, com $79 \%$ dos códigos de ação observados ( de um total de 9712) centralizados num único usuário, o qual cometeu em média 5,7\% de erros.

QUADRO 5: Acessibilidade: Índice de Erros e Niveis dos Códigos de Açáo nos Menus

\begin{tabular}{|lrrrr|}
\hline Gerador $\rightarrow$ & \multicolumn{2}{c}{ Não Integrado } & \multicolumn{2}{c|}{ Integrado } \\
& Quaant. & $\%$ & Quant. & $\%$ \\
\hline Total códigos de ação observados & 3404 & & 9712 \\
\hline Códigos de ação errados & 295 & 8,7 & 610 & 6,3 \\
\hline Uso dos códigos de ação (sem erro) nos menus: & 3109 & & 9102 & \\
- primeiro nível & & 24,0 & & 80,7 \\
- segundo nível & & 43,7 & & 17,8 \\
- terceiro nível & & 32,4 & & 1,5 \\
\hline
\end{tabular}

QUADRO 6: Açఠes Realizadas com o Gerador e os SAD

\begin{tabular}{|c|c|c|}
\hline Gerador $\quad \rightarrow$ & $\begin{array}{l}\text { Não Integrado } \\
\text { Quant. } \%\end{array}$ & $\begin{array}{l}\text { Integrado } \\
\text { Quant. } \%\end{array}$ \\
\hline - Total de Açōes Observadas & 425 & 2463 \\
\hline $\begin{array}{l}\text { - Açóes independentes da realização } \\
\text { e uso dos SAD }\end{array}$ & 45 & 52 \\
\hline $\begin{array}{l}\text { - Açöes dependentes da realização e } \\
\text { uso dos SAD }\end{array}$ & 55 & 48 \\
\hline $\begin{array}{l}\text { Açōes mais freqüentes no uso } \\
\text { do GSAD não integrado: } \\
\text { 1. Carregar arquivos na memória } \\
\text { 2. Atualizar os dados do SAD } \\
\text { 3. Modificar dados e modelo } \\
\text { 4. Imprimir } \\
\text { 5. Carregar gerador } \\
\text { 6. Apresentar modelo na tela }\end{array}$ & $\begin{array}{r}27,3 \\
12,9 \\
12,2 \\
12,2 \\
7,5 \\
6,4\end{array}$ & \\
\hline $\begin{array}{l}\text { Ações mais freqüentes no uso do } \\
\text { GSAD integrado: } \\
\text { 1. Fechar frame (quadro) } \\
\text { 2. Modificar dados e modelo } \\
\text { 3. Abrir frame (quadro) } \\
\text { 4. Deletar frame (quadro) } \\
\text { 5. Carregar arquivos na memória } \\
\text { 6. Imprimir }\end{array}$ & & $\begin{array}{r}18,8 \\
13,4 \\
12,9 \\
9,9 \\
7,4 \\
7,2\end{array}$ \\
\hline
\end{tabular}


A necessidade de declarar o tipo de caracteres a digitar quando do emprego de caracteres alfabéticos ocasionou $25,4 \%$ (de um total de 296) dos erros cometidos com o GSAD não integrado. $20,6 \%$ das ações digitar código alfabético foram erradas, o que revela um problema de concepção do gerador. No uso do gerador integrado não foi observado nenhum erro com tanto destaque.

Por sua vez, a observação do nível em que se encontram os códigos de ação utilizados nos menus dos geradores - ver quadro 5 - revelou que o maior número de códigos de ação estão situados num nivel inferior do menu do gerador não integrado - 76,1\% nos segundo e terceiro níveis. No GSAD integrado somente $19,3 \%$ dos códigos de ação empregados estavam situados nos segundo e terceiro níveis. Constata-se, pois, que no GSAD não integrado os usuários foram obrigados a realizar um número maior de operações para obter uma determinada ação, com uma conseqüente perda de tempo.

\section{Desenvolvimento e Uso dos SAD Específicos}

O desenvolvimento e o uso dos SAD específicos foram observados a partir das ações definidas na figura 2 e a partir dos códigos de ação dos geradores - menus e submenus, comandos especiais, teclas de função - utilizados. As observações sobre as ações dos usuários estão apresentadas no quadro 6 .

A classificação das ações em dependentes ou não do processo de desenvolvimento e uso de SAD específicos revelou que $45 \%$ das ações realizadas com o gerador não integrado são independentes contra $52 \%$ das ações realizadas com o in-

\section{QUADRO 7: Uso dos Códigos de Ação}

\begin{tabular}{|c|c|c|c|c|}
\hline Gerador $\rightarrow$ & \multicolumn{2}{|c|}{$\begin{array}{l}\text { Não Integrado } \\
\text { Quant. } \%\end{array}$} & \multicolumn{2}{|c|}{$\begin{array}{l}\text { Integrado } \\
\text { Quant. } \%\end{array}$} \\
\hline $\begin{array}{l}\text { Códigos de ação } \\
\text { - Utilizados } \\
\text { - Disponíveis }\end{array}$ & $\begin{array}{r}56 \\
107\end{array}$ & 52 & $\begin{array}{r}88 \\
131\end{array}$ & 67 \\
\hline $\begin{array}{l}\text { Funções } \\
\text { - Utilizadas } \\
\text { - Disponíveis }\end{array}$ & $\begin{array}{r}8 \\
40\end{array}$ & 20 & $\begin{array}{r}17 \\
145\end{array}$ & 12 \\
\hline $\begin{array}{l}\text { Códigos de ação mais treqüentes } \\
\text { no uso do GSAD não integrado: } \\
\text { 1. Dados } \\
\text { 2. Código alfabético ("labels") } \\
\text { 3. Tecla ESC (anula) } \\
\text { 4. Fórmula matemática } \\
\text { 5. Gravação arquivo em disquete } \\
\text { 6. Carregar arquivo para memória } \\
\text { 7. Copiar de } \\
\text { 8. Copiar para } \\
\text { 9. Copiar à direita } \\
\text { 10. Erro no código alfabético }\end{array}$ & & $\begin{array}{r}29,3 \\
10,7 \\
6,8 \\
5,0 \\
3,7 \\
3,6 \\
3,6 \\
3,4 \\
2,8 \\
2,2\end{array}$ & & \\
\hline $\begin{array}{l}\text { Códigos de ação mais freqüentes } \\
\text { no uso do GSAD integrado } \\
\text { 1. Abrirffechar quadro (frame) } \\
\text { 2. Definir região de trabalho } \\
\text { 3. Copiar } \\
\text { 4. Entrar no quadro (frame) } \\
\text { 5. Zoom } \\
\text { 6. Recalcular } \\
\text { 7. Subir para a borda do quadro } \\
\text { 8. Apagar } \\
\text { 9. Correção de fórmula } \\
\text { 10. Dados }\end{array}$ & & & & $\begin{array}{r}10,2 \\
9,4 \\
8,8 \\
6,9 \\
6,1 \\
5,7 \\
5,5 \\
5,0 \\
4,3 \\
4,2\end{array}$ \\
\hline
\end{tabular}


tegrado. Para este último, qutro das seis ações empregadas com maior freqüência independem do processo de realização e de uso dos SAD - são ações ligadas à manipulação do software, dos arquivos e do microcomputador. Esta relação mostra que um esforço para melhorar a acessibilidade dos GSAD deve ser realizado a nível do software propriamente dito e também a nível do sistema operacional e do funcionamento dos microcomputadores e de seus periféricos.

Os códigos de ação mais utilizados durante o processo de gestão orçamentária figuram no quadro 7.

$\mathrm{O}$ índice geral de utilização dos códigos de ação disponíveis nos geradores $-52 \%$ para o não integrado e $67 \%$ para o integrado - indica um uso satisfatório destes recursos. A baixa utilização das funçס̃es de programação - $20 \%$ do disponível no GSAD não integrado e $12 \%$ no integrado está relacionada com o tipo de abordagem dada ao problema e com o apoio à decisão demandado, quais sejam:

a realização de modelos orçamentários não sofisticados em termos de interação homemmáquina;

o uso destes modelos para realizar simulações das conseqüências de determinadas decisões;

- a não utilização de modelos de análise financeira, para os quais existe uma série de funções.

Os códigos de ação dos geradores podem ser classificados em "ligados ao conteúdo do modelo" - dados, fórmulas -, "ligados à realização do modelo" - copiar, anular, apagar etc. -, "ligados às peculiaridades do gerador", principalmente em termos da gestão dos quadros (frames) e, finalmente, "ligados ao uso de suporte computadorizado" - gravar arquivo, carregar software e arquivo na memória etc. Levando em consideração essa classificação, a análise dos dez códigos de ação utilizados com maior freqüência nos dois tipos de geradores permite os seguintes comentários: os códigos mais usados no GSAD não integrado são ligados ao conteúdo do modelo propriamente dito $-47,2 \%$ do total ;

- os códigos mais usados no GSAD integrado são ligados à realização dos modelos - $28,9 \%$ - e à gestão dos quadros (frames) do software $28,7 \%$. Estes últimos exigem, pois, uma atenção especial quando do treinamento do usuário.

Cabe assinalar também uma nítida diferença existente na operação copiar, a qual ocorre com grande freqüência quando da realização dos modelos. No GSAD não integrado foram observados três códigos de ação diferentes, entre os dez mais freqüentes, para realizar esta operação: copiar de-para, copiar à direita, copiar para baixo. Estes códigos estão no nível três do menu. No GSAD integrado foram empregados um, no máximo dois códigos diferentes: copiar e definir região. Estes se encontram no nível um, em teclas de função. Como uma das conseqüências, constatou-se que $9,8 \%$ dos códigos copiar do gerador não integrado apresentaram erro contra somente $5 \%$ do gerador integrado.

\section{GSAD e Apoio à Decisáo}

O apoio à decisão fornecido pelos GSAD nas diferentes fases do processo decisório está apresentado no quadro 8. $O$ apoio foi medido a partir das ações realizadas pelos usuários nas diferentes etapas do processo de gestão orçamentária.

A utilização mais intensiva do GSAD integrado na fase de inteligência - $23 \%$ contra $10 \%$ do GSAD não integrado - confirma-se pelo número de modelos gráficos desenvolvidos em número de 27 -, destinados em grande parte à análise de dados do passado da empresa. Ao todo, foram desenvolvidos 56 modelos pelos usuários do gerador integrado, contra somente 10 do gerador não integrado.

A existência do módulo de processamento de gráficos acabou possibilitando um apoio à decisão mais homogêneo ao processo de gestão orçamentária pelo GSAD integrado. Por outro lado, os usuários foram questionados sobre as razões do não uso de outros módulos do gerador processador de textos, gerenciador de dados,

QUADRO 8: Açб́es Realizadas Durante o Processo Decisório

\begin{tabular}{|lcc|}
\hline $\begin{array}{c}\text { Gerador } \rightarrow> \\
\text { Fase do processo decisório }\end{array}$ & $\begin{array}{c}\text { Não Integrado } \\
\text { em \% }\end{array}$ & $\begin{array}{c}\text { Integrado } \\
\text { em \% }\end{array}$ \\
\hline - Inteligência & 10 & 23 \\
- Modelagem & 51 & 34 \\
- Escolha & 39 & 43 \\
\hline
\end{tabular}


organizador de idéias -, os quais potencialmente poderiam contribuir em termos de apoio à decisão. Segundo eles, o processador de textos não foi utilizado, apesar da necessidade de elaborar relatórios durante o processo de orçamentação, em razão da indisponibilidade do GSAD fora do recinto da simulação e em razão do conhecimento insuficiente deste módulo por parte do encarregado da redação dos mesmos. $O$ processador de textos havia sido incluído no programa de treinamento inicial, e o seu não domínio pode ser atribuído à falta de continuidade do trabalho com este módulo. O gerenciador de dados aparentemente não se adequou ao processo de gestão orçamentária e o uso do organizador de idéias sofreu com as restrições de memória útil disponível para o GSAD.

Cabe ressaltar que os usuários de ambos os geradores empregaram ferramentas de previsão - regressão múltipla - durante a fase de inteligência do processo decisório. Estes foram julgados interessantes em função da disponibilidade de informações sobre o passado da empresa.

\section{PERSPECTIVAS PARA O DESENVOLVIMENTO DOS GSAD}

Os resultados apresentados na seção anterior foram obtidos em laboratório, em condiçōes simuladas. Por um lado, este fato traz problemas de validação da pesquisa mas, por outro lado, torna possível uma observação mais detalhada e continuada do uso de GSAD num processo de gestão orçamentária. Este processo, na vida real, é longo e relativamente difuso nas organizaçōes, o que dificulta o seu estudo. A partir das observaçōes realizadas, cuja análise é ainda parcial, são apresentadas recomendaçð̄es para o desenvolvimento futuro dos geradores por parte das softwarehouses e para a sua utilização nas organizaçōes.

\section{Desenvolvimento dos GSAD pelas Software- houses}

\subsection{Desenvolvimento da acessibilidade}

A análise da acessibilidade, apresentada na seção "Uso dos GSAD e Acessibilidade", evidenciou alguns problemas relacionados com o conceito de utilização fácil e eficiente, entre as quais cabe destacar os problemas encontrados na interrelação software-hardware, os problemas de códigos de ação que induzem erros - a obrigatoriedade da definição de código alfabético no gerador não integrado -, o grande número de niveis encontrados nos menus e a facilidade de uso inicial do GSAD.
Quanto ao primeiro problema, a compatibilização da configuração micro-impressorasoftware é realizada de uma maneira pouco prática e amigável no GSAD não integrado. Pacotes de software mais recentes permitem efetuar esta compatibilizaçăo via menu. Neste caso, o problema que resta a resolver para as softwarehouses é o de como fazer chegar às mãos do usuário os programas de compatibilização das impressoras mais recentes, tendo em vista a diversificaçăo e a expansão deste segmento do mercado de hardware. Uma outra solução pode ser obtida pela perfeita integração hardware-software, como o preconiza a política de Apple Co., com a sua linha MacIntosh.

Em termos de integração hard e software, o GSAD integrado teve problemas com a memória disponível no micro. A solução deste problema passa pelo desenvolvimento do sistema operacional DOS, o mais difundido entre os micros PC 16 bits, permitindo que ele acesse uma memória maior. A solução encontrada com o novo micro PS-2 e seu sistema operacional OS-2, além de não estar disponível no Brasil, é bastante cara, e a utilização de memória virtual em disco rígido é somente um paliativo.

Outros problemas, não estudados nesta pesquisa, surgem com uma necessidade maior de comunicação e a possibilidade de importar e exportar dados e modelos, viabilizando o conceito de SAD para Grupos.

O número de açōes necessárias para a operacionalização do suporte computacional, praticamente igual ao das ações necessárias para a modelagem dos SAD, deve suscitar reflexões para o desenvolvimento de GSAD, no sentido de simplificar e reduzir este tipo de operações.

Dois tipos de solução podem ser adotados para resolver o problema dos níveis excessivos nos menus e da má localização de comandos freqüentemente utilizados - por exemplo, os códigos de ação para cópia no GSAD năo integrado. Uma via consiste em propor dois modos de interação com o software, através de menu para usuários não treinados e via comandos diretos para usuários treinados e que usam o gerador regularmente. Esta solução já existe no software dBASE III Plus, dedicado a problemas de gerenciamento de dados. A idéia pode ser transposta para os GSAD para planejamento orçamentário. Uma segunda solução pode ser obtida através de um estudo mais criterioso do posicionamento dos comandos nos menus, colocando os códigos de ação empregados com mais freqüência nos níveis superiores ou em teclas de função, permitindo a diminuição do número de operações. 
Com o objetivo de tornar o GSAD mais acessível desde o primeiro contato do usuário, torna-se imperioso reduzir a sua complexidade. Uma arquitetura mais aberta e modular do GSAD, que será discutida no item seguinte, pode contribuir para isso.

\subsection{Integração de funçōes}

A disponibilidade de um maior número de funç̃̃es no GSAD integrado oportunizou um maior apoio à decisão na fase de inteligência do processo decisório. Segundo Treacy 13 , as funções existentes nos GSAD cobrem razoavelmente bem as atividades de modelagem do problemas restando cobrir melhor as necessidades de análise ad hoc, quando existem problemas específicos. Entre as funções que podem ser integradas para o tipo de problemas estudado, encontram-se modelos de previsão - que foram empregados, de maneira autônoma, pelos usuários dos GSAD não integrado e integrado e modelos de análise estatística.

A fase de escolha poderia ser melhor apoiada com a integração de modelos de otimização oriundos da Pesquisa Operacional e de modelos que auxiliam a arbitragem das decisões, baseados na análise multicritérios. Em termos de funções de otimização, pode ser citado o software Vino, compatível com a planilha Lotus 1,2,3.

A medida que mais funçōes, que favorecem a análise ad hoc, são integradas no GSAD, aumenta a dificuldade de utilização dos mesmos. Uma via de desenvolvimento a ser pesquisada consiste na inclusão de um módulo inteligente de assistência ao usuário ${ }^{14}$. Este é formado por um banco de conhecimentos específicos para a pilotagem do gerador, e pode auxiliar o usuário/ tomador de decisão na escolha de modelos de análise pertinentes à problemática.

Por outro lado, a não utilização de módulos do gerador integrado, potencialmente úteis para o tipo de problema tratado - o módulo processamento de texto, por exemplo -, mostra que a maior complexidade deste tipo de GSAD não foi inteiramente dominada. O tipo de treinamento dado aos usuários teve como características principais: duração de três dias, abordagem de todos os módulos, com exceção da comunicação, estudo de $69 \%$ dos códigos de ação e $13 \%$ das funções. Os usuários não iniciados em informática e, principalmente, aqueles que não utilizam o gerador de maneira intensiva após o treinamento inicial têm a necessidade de um produto mais simples. Este poderia ser desenvolvido em torno de uma arquitetura mais aberta e modular, permitindo a integração de novos módulos à medida que se faz sentir a sua necessidade, conservando contudo os códigos de ação de base. O produto MS-Windows, um software do tipo integrador, é um exemplo da via de desenvolvimento que pode ser seguida.

\section{Implementaçăo dos GSAD}

A análise da utilização dos GSAD em gestão orçamentária destacou a importância da criação de uma infra-estrutura condizente para o seu uso por usuários com pouca experiência em informática. Condições muito importantes são a assistência técnica, em termos de presença e competência, e a disponibilidade permanente dos geradores em número suficiente, garantindo a eficácia do uso dos mesmos. A pressão do tempo ( os prazos ) associada ao processo de gestão orçamentária faz com que interrupções do processo decisório sejam mal recebidas pelos usuários. Nesse sentido, abordagens do tipo Centro de Informações, criadas para difundir a informática para o usuário final nas organizações, podem ser muito úteis.

Este trabalho apresentou resultados obtidos a partir da análise de um processo de orçamentação simulado em laborátorio. Um estudo mais aprofundado da problemática descrita, a ser realizada nas próprias organizações, permitirá uma avaliação mais precisa da importância relativa de cada um dos aspectos mencionados acima.

13. TREACY, Michael. "Future directions in DSS technology". In: Center for Information Systems Research Working Paper n. 123. Sloan School of Management, MIT, january, 1985, 28 páginas.

14. TRAHAND, Jacques e HOPPEN, Norberto. "Sistemas Especialistas e apoio à decisão em Administração". In: Revista de Administração, vol. 23, $n^{2} 2$, abril-junho, 1988, pp. 11-20.

ABSTRACT: In this paper the authors present a longitudinal study about the use of Decision Support Systems Generators in a Budgeting process. The study comprises: 1. analysis of the userfriendliness concept of a generator; 2. analysis of the development process of DSS using generators; $e$ 3. analysis of the support provided by the DSS to the decision process. Some suggestions for future development of
$D S S$ generators are also presented. KEY WORDS: Decision Support, Decision Support Systems, Decision Support Systems Generators,
Budgeting Process. 